\title{
Talking About End-of-Life Care: How Should Physicians Act
}

\author{
Nurunnabi $\mathrm{ASM}^{1}$, Ahmad $\mathrm{N}^{2}$, Chakma $\mathrm{S}^{3}$, Asaduzzaman $\mathrm{M}^{4}$, Mohammad $\mathrm{A}^{5}$
}

\begin{abstract}
Physicians should be adept in communication and familiar with the various end-of-life issues and their implications. However, physicians in Bangladesh usually receive very little training or guidance on how to communicate with the dying patients and their families. Since death is a common phenomenon, for physicians in their day-to-day practice, it sometimes becomes difficult to engage in end-of-life discussions in a death-averse society. This review paper aims to discuss a pragmatic step-by-step approach to discussing end-of-life care in a Bangladeshi context maintaining local social and cultural views. Specifically outlined in each of these four steps, a physician should seek a common understanding with the patient and family. Moreover, if any disagreement arises, overt conflict can often be avoided by reviewing what was discussed earlier with the patient or family. We all know that providing a supportive care for a dying patient is challenging. However, when it is done well, it becomes a meaningful and gratifying experience for the physician. As we know, helping someone die in comfort and with dignity signifies a good death and one of the best gifts of life that theoretically leads him/her to rest in peace.
\end{abstract}

CBMJ 2020 January: vol. 09 no. 01 P: 38-42

Key words: End-of-life care, breaking bad, death and dying, physician-patient relationship, professionalism.

\section{Introduction}

In a developing country like Bangladesh, physicians are trained to fight illness; however, death is a common phenomenon they experience in front of their eyes every day. While working in resource poor settings, they usually receive very little training or guidance on how to communicate with the dying patients and their families. Since death is a common phenomenon, for a physician, it sometimes becomes difficult to engage in end-of-life discussionsin a death-averse society. ${ }^{1}$ However; patients need the truth even when it tells them about their death. A death notice is a shock and a pain and yet patients can derive benefit from being told the truth even about their own death. ${ }^{2-5}$ Over past decades, truth-telling and patient autonomy have become near moral absolutes in most western societies like US or Canada, while in the other side of the globe, e.g. in Japan, in more familycentric settings, personal autonomy hardly becomes the foremost ethical principle wished for by patients or their families. ${ }^{6-8}$ Being a South Asian developing country, Bangladesh has a long standing social and cultural inheritance of family-centered truth telling, when a patient is suffering from any end-stage or non-curable disease. Providing them with truthful information is to enable them to make correct decisions which will benefit their overall health. ${ }^{5,9}$ Besides, physicians must not bar patients from receiving potentially upsetting information as they will be held responsible if patients get

1. Dr. Abu Sadat Mohammad Nurunnabi, Erasmus Mundus Master of Bioethics student, Section of Ethics, Philosophy and History of Medicine, Radboud Universiteit Nijmegen, the Netherlands.

2. Prof. Nezamuddin Ahmad, Professor and Director, Centre for Palliative Care, Bangabandhu Sheikh Mujib Medical University (BSMMU), Dhaka-1000, Bangladesh.

3. Dr. Shuchana Chakma, Medical Officer, Department of Obstetrics \& Gynaecology, Chattogram Maa-O-Shishu Hospital, Chittagong4100, Bangladesh.

4. Dr. Md. Asaduzzaman, Assistant Registrar, Department of Medical Oncology, National Institute of Cancer Research \& Hospital (NICRH), Dhaka-1212, Bangladesh.

5. Dr. Arif Mohammad, Assistant Registrar, Department of Urology, Shaheed Sheikh Abu Naser Specialized Hospital, Khulna-9100, Bangladesh.

Address of correspondence:

E-mail: shekhor19@yahoo.com 
injured due to failure to disclose. ${ }^{9}$ Models of truth telling include partial or complete nondisclosure (enhancing beneficence), full disclosure or non-disclosure (respecting patients' autonomy), and individualized disclosure (emphasizing a more nuanced, patient-centered, and guided communication). ${ }^{10}$ We will try to discuss four steps of talking end-of-life care with some of the crucial points maintaining the social, and cultural views in a Bangladeshi context. Specifically outlined in each of these four steps, a physician should seek a common understanding with the patient and family. Moreover, if any disagreement arises, overt conflict can often be avoided by reviewing what was discussed earlier with the patient or family. For example, if a patient has unreasonable expectations regarding the treatment plan, it is helpful to revisit his perceptions of prognosis and his end-of-life goals.

\section{Step 1. How to Initiate Discussion:}

A Supportive physician-patient relationship provides an important ground work to ensure end-of-life care. It also builds trust and confidence. Patients and families can speak more openly, decide confidently when they feel that their doctors have empathy and compassion towards them. ${ }^{5}$ A caring connection can be enhanced by recognizing the stresses that illness imposes on a patient and family. However, the task of truth-telling is not an easy job. There are many reasons, may be with varying degrees of justification, not to disclose complete information in different clinical context and clinical judgments. Those include physicians' discomfort, concern for its negative impact on patient, uncertainty about prognosis and illness trajectory, lack of time, requests from the patient or family to withhold information. ${ }^{6-8}$ Now the matter is how to start discussion. Usually the attending physician or the respective unit head convey the information to the patient and family. Every patient needs an explanation of his illness that will be understandable and convincing to him if he is to cooperate in his treatment or be relieved of the burden of unknown fears. ${ }^{6,7}$ This is true whether it is a question of giving a diagnosis in a hopeful situation or of confirming a poor prognosis. Hence, the physician should start the discussion keeping all points in the mind. By encouraging a patient to speak openly, the physician helps the subject of death being less of a taboo. Patients and families may feel comfortable continuing conversations even outside the doctor's office or hospital. ${ }^{11}$ When the patient becomes sicker, all parties find it easier to reopen the discussion. ${ }^{12}$ The physician elicits general thoughts about end-of-life preferences and help them choose. Sometimes he needs to call for a surrogate decision maker from close family members or relatives. ${ }^{11}$

\section{Step 2. Being Honest About Disease Course and Prognosis:}

Patients and families often require repeated explanations in order to understand a medical problem. Comprehension is enhanced with each repetition. ${ }^{5}$ For physician, with all medical discussions, it is best to use simple, everyday language and to avoid technical wording as far as possible. During times of high anxiety, concentration and comprehension may be further limited. ${ }^{5}$ Moreover, decisions about withholding or withdrawing life-sustaining treatment that is considered futile or not medically indicated should be discussed with the patient, or the substitute decisionmaker on behalf of an incapable patient and/ family. ${ }^{4,11}$ It is true that some patients who are given a cancer diagnosis and a prognosis of death may use denial for a while and the bad news may have to be repeated, but the use of denial can be turned into a coping strategy subsequently. ${ }^{11,13}$ But we think those patients still would not prefer to be lied to or, as truth remains important to them for further actions. ${ }^{13,15}$ And some patients are eager to know about the uncertainties of their medical condition as well as the established facts around prognosis. ${ }^{5}$ In such cases, when physicians honestly acknowledge their prognostic limitations, 
they become also able to build trust. ${ }^{13,14}$ It usually helps to go for the next steps.

\section{Step 3. Helping Patients Selecting End-of-life Goals:}

Once a patient and family acknowledge that death is approaching, the physician's role is to facilitate an open discussion about desired medical care and remaining life goals. ${ }^{5}$ Although general thoughts can be explored in initial discussions, several factors mediate against making detailed end-of-life decisions significantly in advance of one's death. First, patients' preferences may not be durable over time. Although some have concluded that advance directives can be stable for months to years, others have noted significant preference changes, even over short periods of time as severity of illness worsens. ${ }^{5,16}$ Other investigators have found that preferences can fluctuate depending on how outcomes of therapy are described. ${ }^{17}$ Thus, one must respect that an advance directive should never supercede the currently stated interests of a patient. $^{18}$

As death nears, most patients share similar goals: maximizing time with family and friends, avoiding hospitalization and unnecessary procedures, maintaining functionality, and minimizing pain. Some patients have special requests, such as important visits, desired conversations, or the wish to involve hospice or religious counsel in their final care. Earlier discussions about general desires need to be revisited, as the immediacy of a worsening illness may modify one's feelings and thoughts. Thus, a holistic assessment can result in a plan which records the wishes and decisions of a person at the end of life. It has become customary in developed countries that holistic care planning meetings take place, in which all members of the team can contribute, and at which the views of the patient and the family are presented, and are considered essential to develop a plan of care for each individual patient. $^{19-20}$

\section{Step 4. Facilitating and Developing Holistic Treatment Plan:}

Seriously ill patients and family members define several factors while talking quality end-of-life care. $^{16}$ The most important elements revealed are: trust and confidence in the treating physician(s), effective communication, avoidance of unwanted life support, easing pain and giving holistic support, continuity of care and life completion. ${ }^{3,4,16-22}$ However, variations may be found in the perception or need for customized or individualized approaches to providing end-of-life care. ${ }^{16}$ Holistic care strives to encompass four core areas of a patient's life: physical, emotional, social, and spiritual. It involves recognition that the needs of a dying patient go beyond just the clinical and physical. By addressing problems and needs in each of these areas, holistic care improves the patient's overall quality of life. The preferences of terminally ill patients trend toward less-aggressive care as their illnesses progress. Most patients believe that, at some point, life-prolonging interventions should be limited ${ }^{5,16,22}$; patients may ask for "do not resuscitate" or "no advanced life support". This is known as advance directive. It helps all stakeholders to act during the last stage of life. Reducing physical pain is another important topic. Experts believe that care for someone who is dying should focus on relieving pain without worrying about possible long-term problems of drug dependence or abuse. ${ }^{17,18}$ Physicians should inform patients and families that pain is easier to prevent than to relieve, and severe pain is hard to manage. ${ }^{18}$ As an illness progresses, the physician is challenged to respond to the pains and fears a patient and family are experiencing. We want to introduce thoughts on "fearless healing", which means initiating an end-of-life discussion with a terminally ill patient or discussing a worsening prognosis with a failing, hospitalized patient. Sometimes fearless healing means listening to a patient talk about his physical decline, his emotional and spiritual suffering. ${ }^{23}$ Even when curative therapy is no longer effective, 
the physician's involvement always remains a powerful source of comfort for the patients and families. A physician should try to know of any personal, religious or cultural beliefs involved with the patient or family; cultural and religious differences are to be respected and treatment planned in a culturally sensitive manner. ${ }^{10,23-25}$ Spiritual needs can include ethical concerns (e.g. a need for forgiveness), questions about meaning (e.g. a need to 'make sense' of what's happening) or specifically religious issues (e.g. a wish to see an Imam, or a Priest). ${ }^{23-25}$

\section{Recommendations:}

In a progressive health care system, if a patient is in a tertiary care facility, the problem of deciding just what to disclose is compounded by the difficulty of deciding the right person to make the disclosure. ${ }^{3} \mathrm{~A}$ patient can be attended by any number of professional staff members, each of whom has a professional code and some sense of responsibility for telling the truth. In Bangladesh, traditionally, the attending physician or unit head alone seems responsible for all communication. However, in developed countries today, nurses and social workers also claim responsibility for truthful communication with patients and families. Management of terminally ill patients involves not only symptomatic management but also discussion and communication regarding their prognosis and the pertinent end-of-life care decisions. ${ }^{2,3,15}$ The physicians should be adept in communication and familiar with the various end-of-life issues and their implications. ${ }^{7,12} \mathrm{We}$ recommend sincere attention by the authorities concerned for physicians' competences in end-of-life care through different initiatives to improve education and training at all levels. ${ }^{12-14} \mathrm{We}$ also recommend that professionalism and ethics, cultural competence, awareness of diversity, and most importantly, cultural humility (a process that brings into check the inherent imbalance of the physicianpatient communication), should be included in the undergraduate and postgraduate medical curriculum. ${ }^{12-14,22}$

\section{Conclusion:}

We have tried to discuss a pragmatic stepby-step approach to discussing end-of-life care in this paper. Ensuring good end-of-life care requires both an understanding of how patients and families experience the phenomenon of inevitable death and dying process and a culturally-sensitive communication skill. By acquiring those skills, physicians can enable them to conduct thoughtful discussions in which most decisions can be evolved comfortably and without much controversy with the patients and their families. Providing a supportive care for a dying patient is challenging. However, when it is done well, it becomes a meaningful and gratifying experience for the physician. As we know, helping someone die in comfort and with dignity signifies a good death and one of the best gifts of life that theoretically leads him/her to rest in peace.

\section{References:}

1. Callahan D. Pursuing a peaceful death. Hastings Cent Rep. 1993;23(4):33-8.

2. Saunders CMS. Telling patients. In: Reiser SJ, Dyck AJ, Curran WJ. Ethics in Medicine. Boston: MIT Press; 1977. p.23840.

3. Buckman R. How to Break Bad News: A Guide for Health Care Professionals. Baltimore: Johns Hopkins University Press; 1992. p.15-6.

4. Schneiderman LJ, Jecker NS, Jonsen AR. Medical futility: its meaning and ethical implications. Ann Intern Med. 1990;112(12):949-54.

5. Balaban RB. A physician's guide to talking about end-of-life care. J Gen Intern Med. 2000;15(3):195-200.

6. Hancock K, Clayton JM, Parker SM, Wal $\operatorname{der} S$, Butow PN, Carrick $S$, et al. Truthtelling in discussing prognosis in advanced life-limiting illnesses: a systematic review. Palliat Med. 2007:21(6):507-17. 
7. Hébert PC, Hoffmaster B, Glass KC, Singer $P A$. Bioethics for clinicians: 7. Truth telling. CMAJ. 1997;156(2):225

8. Mazur DJ, Hickam DH. The effect of physician's explanations on patients' treatment preferences: five-year survival data. Med Decis Making. 1994;14(3):255-8.

9. Lynn J, Teno JM, Phillips RS, Wu AW, Desbiens N, Harrold J, et al. Perceptions by family members of the dying experience of older and seriously ill patients. SUPPORT Investigators. Study to Understand Prognoses and Preferences for Outcomes and Risks of Treatments. Ann Intern Med. 1997;126(2):97-106.

10. Feinberg $A W$. The care of dying patients. Ann Intern Med. 1997;126(2):164-5.

11. Reust CE, Mattingly S. Family involvement in medical decision making. Fam Med. 1996;28:39-45.

12. Davis RM, Genel M, Howe JP, Karlan MS, Kennedy WR, Numann PA, et al. Good care of the dying patient. JAMA. 1996;275(6):474-8.

13. Rabow MW, Hardie GE, Fair JM, McPhee SJ. End-of-life care content in 50 textbooks from multiple specialties. JAMA. 2000;283(6):771-8.

14. Kaasa S, Loge JH. Quality of life in palliative care: principles and practice. Palliat Med. 2003;17(1):11-20.

15. Pantilat SZ. Communicating with seriously ill patients: better words to say. JAMA. 2009;301(12):1279-81.

16. Heyland DK, Dodek $P$, Rocker $G$, et al. What matters most in end-of-life care: perceptions of seriously ill patients and their family members. CMAJ. 2006;174(5):62733.

17. Gonzales MJ, Pantilat SZ. Pain at the end of life. Hosp Med Clin. 2012;1(1):e109-23.

18. Bengoechea I, Gutiérrez SG, Vrotsou K, Onaindia MJ, Lopez JM. Opioid use at the end of life and survival in a Hospital at Home unit. J Palliat Med. 2010;13(9):107983.
19. McCarthy EP, Phillips RS, Zhong Z, Drews RE, Lynn J. Dying with cancer: patients' function, symptoms, and care preferences as death approaches. J Am Geriatr Soc. 2000;48(S1):S110-21.

20. Lynn J, Teno JM, Phillips RS, Wu AW, Desbiens N, Harrold J, et al. Perceptions by family members of the dying experience of older and seriously ill patients. SUPPORT Investigators. Study to Understand Prognoses and Preferences for Outcomes and Risks of Treatments. Ann Intern Med. 1997;126(2):97-106.

21. Sulmasy DP. A biopsychosocial-spiritual model for the care of patients at the end of life. Gerontologist. 2002;42(3):24-33.

22. Workman S. A communication model for encouraging optimal care at the end of life for hospitalized patients. QJM. 2007;100(12):791-7.

23. Puchalski CM, Lunsford B, Harris MH, Miller $R T$. Interdisciplinary spiritual care for seriously ill and dying patients: a collaborative model. Cancer J. 2006;12(5):398-416.

24. Pembroke NF. Appropriate spiritual care by physicians: a theological perspective. J Relig Health. 2008;47(4):549-59.

25. Daaleman TP, Usher BM, Williams SW, Rawlings J, Hanson LC. An exploratory study of spiritual care at the end of life. Ann Fam Med. 2008;6(5):406-11. 